\title{
AS EXPOSIÇÕES INTERNACIONAIS DE ARTE BRASILEIRA: discursos, práticas e interesses em jogo
}

\author{
Ana Leticia Fialho*
}

\begin{abstract}
Resumo: Nos anos 90, a presença da arte brasileira tornou-se cada vez mais freqüente na cena artística internacional. Curadores e demais agentes internacionais vêm adotando um discurso politicamente correto, segundo o qual as fronteiras entre centro e periferia, que sempre organizaram o campo artístico internacional, teriam desaparecido, permitindo assim a valorização da arte de países periféricos pelas instituições mais prestigiosas dos países centrais. Contudo, a maior parte dos diferentes eventos em torno da arte brasileira servem muito pouco à democratização do campo artístico ou à difusão da cultura brasileira no plano internacional. De fato, eles refletem a globalização em seus efeitos perversos, servindo para aumentar o prestígio e o poder econômico de algumas poucas instituições e indivíduos, limitando a cultura brasileira à reprodução de seus estereótipos. Neste artigo, para demonstrar essa idéa, analisam-se em detalhe quatro exposições de arte brasileira organizadas na exterior: Brazil Body and Soul (Museu Guggenheim, Nova Yorque), Hélio Oiticica Quasi-Cinemas (New Museum, Nova Yorque), Un art populaire (Fundação Cartier, Paris), Tunga/Mira Schendel (Galeria Nacional Jeu de Paume, Paris).
\end{abstract}

Palavras-chave: Brasil, arte, cultura, exposição internacional.

\footnotetext{
Doutora pela École des Hautes Études en Sciences Sociales (EHESS) Paris (Bolsa Capes), Especialista em Gestão Cultural (Université de Lyon 2), Fundadora do Grupo de Estudos Interdisciplinares de Arte e Cultura (2002). E-mail: analeticiaf@wanadoo.fr Apresentado no Rencontre Culture au Brésil: développement, acteurs et perspectives, Paris, 9 et 10 février 2004.
}

Artigo recebido em 4 out. 2005; aprovado em 10 dez. 2005. 


\section{Introdução}

O Brasil nunca pertenceu ao mapa internacional das artes visuais. A organização deste sempre foi polarizada. Uma forte tradição européia dominou até os anos $40^{1}$ e, a partir da Segunda Guerra Mundial, os Estados Unidos passam a ter poder e influência crescentes. $^{2}$

Hoje os Estados Unidos e alguns países europeus detêm o monopólio do mercado e das instâncias de legitimação, compondo um eixo central bipolar (Quemin, 2002). Mas se até os anos 60, talvez 70 , os discursos nacionalistas eram bem mais abertos, e cada país tentava afirmar sua superioridade em relação aos outros, ${ }^{3}$ hoje, num mundo politicamente correto, o discurso é mais sutil.

Observamos essa mudança a partir dos anos 70, quando o circuito internacional das artes começa a se abrir a outros países e, até mesmo, a outros continentes. As determinantes dessa abertura são múltiplas ${ }^{4}$ e estão ligadas a especificidades locais - como, por exemplo, os movimentos de imigração ${ }^{5}$. Mas o fator mais importante a ser considerado é certamente o aumento da demanda de 'novidades' por parte dos mercados - acadêmico, institucional, e o mercado stricto sensu. ${ }^{6}$

Essa necessidade de reciclagem, por parte dos diversos agentes do sistema internacional das artes, saturados da modernidade ocidental e dos grandes mestres europeus, provoca assim a 'descoberta' das artes da América Latina, da África, da Oceania, etc. ${ }^{7}$

Mais ou menos na mesma época, na América Latina, um movimento de resistência se constitui. Esse grupo - composto por artistas, críticos e historiadores da arte - militava por uma resistência, ao mesmo tempo, aos regimes ditatoriais e à influência dos modelos europeus e norte-americanos. ${ }^{8}$

Hoje, o discurso vigente é outro: politicamente correto e internacional, ele informa os sistemas das artes visuais tanto nos países periféricos quanto nos países centrais. ${ }^{9}$ 
Esse discurso se apresenta em duas versões:

\section{a) Discurso da assimilação/homogeneização}

Segundo essa versão, o elemento nacional deve desaparecer, sendo válidos somente os critérios estéticos, supostamente atemporais e universais.

Os curadores, os galeristas ou os artistas que aderem a esse discurso têm uma tendência, em suas práticas, a considerar a produção artística separadamente do seu contexto político e social - a idéia é que a estética existe acima dos parâmetros da cultura, sendo o papel dos museus apresentar o exemplo da genialidade artística individual (Ramirez, 1996).

A recusa das determinantes territoriais, econômicas e sociais está também presente no discurso dos agentes da cena artística brasileira (sobretudo entre críticos e curadores). A declaração de Agnaldo Farias, curador da Bienal de São Paulo de 2002, é um bom exemplo:

O critério para escolher os artistas brasileiros, à parte a qualidade do trabalho artístico, foi a vontade de demonstrar que a arte brasileira não se limita ao Rio ou a São Paulo. Há bons artistas em todo o país. Arte, quando boa, não tem fronteiras. Não há relação entre concentração de riqueza e qualidade artística. (Estado de S. Paulo, 27 ago 2001).

\section{b) Discurso da diferença}

A segunda versão possível do discurso pró-globalizacão, baseiase na afirmação de características nacionais, regionais ou locais; no elogio da mestiçagem, do multiculturalismo ou até mesmo do exotismo.

A referência mais importante dessa linha de pensamento é Jean Hubert Martin, ${ }^{10}$ curador francês que organizou Magiciens de la Terre $^{11} \mathrm{e}$, mais recentemente, Partage d'exotisme, ${ }^{12}$ dois momentos importantes para a consolidação dessa tomada de posição em favor da diferença. ${ }^{13}$ 
Martin, que é considerado freqüentemente o precursor da abertura do "Ocidente" à produção artística "não-ocidental", ${ }^{14}$ desenvolveu o conceito de "glocal":

Por esse termo eu compreendo a absorção dos impulsos que provêm do mundo inteiro e, ao mesmo tempo, o envio de sinais ao mundo inteiro provenientes de onde estamos. Para melhor compreender a extensão da globalização, é preciso passar por uma boa definição da nossa própria cultura. Só podemos dialogar com o 'outro' na medida em que reconhecemos nossa própria identidade. (Jean Hubert Martin, em entrevista a Art Press, out. 2001).

Quando preparava Les Magiciens de la Terre, Martin viajou muito:

Na América do Sul, especialmente, à parte o Brasil, nós tivemos muitas decepções porque encontramos artistas envolvidos num sistema de arte ocidental, com galerias, museus, etc. E as produções dos artistas nos pareceram muito dependentes de nossos grandes centros, ora, o que procurávamos era outra coisa - algo que pudesse renovar o olhar, renovar o interesse... Não me interessava mostrar que os artistas na América Latina lêem Artforum. (Art Press, maio 1989)

Para os agentes que usam, como J. H. Martin, esse tipo de discurso, os dados identitários são importantes. $\mathrm{O}$ artista da periferia encontra, nesse caso, um lugar no mundo da arte contemporânea sob a condição de demonstrar, explicitamente, sua não-afiliação ao modelo ocidental. Ou seja, deve se comportar como "bom selvagem".

De toda forma, seja qual for a versão adotada, o discurso hegemônico sustenta que a globalização teria finalmente aberto as portas do mercado e das instituições ocidentais à produção artística "não ocidental". Os mais otimistas vêem uma nova geografia artística em formação (Garreta, 2000), na qual o mapa da arte contemporânea seria bem mais diversificado e rico.

Contudo, há uma grande diferença entre os discursos e as práticas dos agentes internacionais. $\mathrm{O}$ mundo das artes visuais permanece um mundo fechado, fortemente hierarquizado, onde os 
países mais fortes afirmam sua superioridade e onde os países periféricos só são chamados para participar a fim de aumentar o valor daqueles que já são super valorizados. ${ }^{15}$

O Brasil tem um papel, ainda hoje, coadjuvante, como muitos outros países. Raramente nós, enquanto brasileiros, reconhecemos isto. Somos constantemente levados por um sentimento de orgulho nacional, um nacionalismo ilusionista que nos dá uma imagem do país que não corresponde àquela efetivamente reproduzida no exterior, e, o que é pior, frequientemente estamos prontos a pagar, e caro, o preço de um péssimo lugar no cenário internacional.

Neste artigo, para sustentar essa idéia, serão analisadas ${ }^{16}$ quatro exposições organizadas em torno da arte brasileira no exterior: Brazil Body and Soul (Guggenheim Museum, New York); Hélio Oiticica Quasi-Cinemas (New Museum, New York); Un art populaire (Fondation Cartier, Paris); Tunga/Mira Schendel (Galerie Jeu de Paume, Paris).

\section{Brazil Body and Soul}

Essa exposição foi apresentada no Guggenheim de Nova Iorque, de 10 de outubro de 2001 a 29 de maio de 2002.

Brazil Body and Soul foi um dos eventos mais ambiciosos e caros $^{17}$ organizado pela Fundação Brasil 500 Anos $^{18}$ e um dos mais midiatizados também. A missão oficial dessa iniciativa era comemorar os 500 anos da 'descoberta' do Brasil, valorizando a diversidade e a riqueza da cultura brasileira no exterior.

À frente dessa super produção estava a Fundação Brasil 500 Anos e o Museu Guggenheim. O governo brasileiro também teve um peso importante no projeto, que contou com o apoio de diversas instituições brasileiras, galerias, colecionadores, artistas e empresas.

Pequena amostra do que foi a Mostra do Descobrimento no Brasil, ${ }^{19}$ a exposição organizada em Nova Iorque optou por exibir 
um grande número de obras, oferecendo um panorama da arte brasileira desde o século XVII até os dias de hoje..$^{20}$ Mais da metade dos objetos era, entretanto, da época barroca.

Segundo o curador-geral da exposição, Edward Sullivan, o barroco é a síntese e a origem da produção cultural brasileira. $\mathrm{Na}$ verdade, o curador adaptou uma de suas "especialidades" - o barroco - à encomenda de última hora - arte brasileira .

Sullivan é professor de história da arte na New York University, autor de um livro sobre arte da América Latina. ${ }^{21}$ Ele é o exemplo perfeito do especialista que encontrou na categoria "Arte da América Latina" uma possibilidade de distinção, tanto no campo acadêmico quanto cultural.

Ele contou com a assistência de Germano Celant, co-curador da exposição e funcionário permanente do Guggenheim. Celant é um personagem que mantém laços com o Brasil. Entre os projetos que ele chefiou está a representação do Brasil na Bienal de Veneza de $2001,{ }^{22}$ trabalhou também com a Bienal de São Paulo ${ }^{23}$ e foi um dos principais articuladores da instalação de uma filial do Guggenheim no Rio de Janeiro.

Um outro aspecto da exposição que é necessário destacar é a participação do arquiteto francês Jean Nouvel, que foi o responsável pela cenografia. Não por acaso, ele também foi convidado a desenvolver o projeto do Guggenheim no Rio de Janeiro.

Segundo muitos críticos, Brazil Body and Soul foi realizada para pressionar o Brasil a construir a filial do Guggenheim no Rio de Janeiro. É preciso lembrar também que esse projeto, finalmente suspenso por força judiciária em resultado da ação movida pelo Ministério Público, já havia custado à cidade do Rio mais de 200 mil dólares. O custo do museu no Rio se elevaria a alguns milhões de dólares e seria financiado majoritariamente por investidores brasileiros, públicos e privados. Segundo um funcionário do Guggenheim, o princípio é simples: 
Como nas grandes redes hoteleiras, o museu oferece o know how, a cidade, a infra-estrutura. Depois, a cidade ganha os benefícios de ter um museu de marca, e o museu fica com os lucros. ${ }^{24}$

De acordo com Julian Zagazagoitia, ${ }^{25}$ um dos responsáveis pela exposição Body and Soul, o Guggenheim, como outros museus de grande porte, organiza sua programação com 4 a 6 anos de antecedência. Por que teria aceitado então organizar a exposição brasileira faltando menos de 2 anos para a inauguração?

Claro que o fato de tratar-se de um projeto já desenvolvido, o que evitou o trabalho de pesquisa (o mais longo da produção) ajudou muito na escolha de realizar a exposição. (Entrevista em Nova Iorque, 14 dez. 2003)

O fato de não ser necessário buscar financiamento também deve ter sido decisivo, embora não mencionado. Como vários outros museus, o Guggenheim tem problemas orçamentários. O museu havia cancelado o projeto de uma grande restrospectiva dedicada a Hélio Oiticica, a mesma que foi apresentada no Museu Witte de With e na Galeria Jeu de Paume em Paris, com curadoria de Catherine David, ${ }^{26}$ devido à falta de verbas. ${ }^{27}$

Brazil Body and Soul, por um lado, evidencia o desejo de projeção na cena internacional de certos agentes brasileiros e também serve de indicador da abertura do campo artístico brasileiros aos "especialistas" internacionais. ${ }^{28}$

No Brasil, o evento teve uma grande repercussão.

A publicidade (espaço na mídia) é, aliás, uma das principais vantagens de exposições realizadas no exterior. Isso possibilita a valorização e o reconhecimento dos artistas (e organizadores) a nível nacional, com as conseqüências econômicas anexas (aumento do valor das obras, aumento do prestígio, multiplicação dos convites para participar de outros eventos, publicações, marketing gratuito).

Como todos tiveram a chance de observar no Brasil, as iniciativas da Brasil Connects sempre tiveram grande impacto midiático. No caso de Brazil Body and Soul, muitos foram os críticos, mas houve também defensores: 
...também é verdade que o conjunto da mostra é impressionante e desperta forte sentimento de orgulho verde-amarelo em quem não tem a alma apequenada por preconceitos caipiras. Uma exposição dessas certamente ajudará a desfazer muitas das idéias equivocadas sobre o Brasil que ainda existem no Primeiro mundo. (Júlio Mariani, jornal Zero Hora, Porto Alegre, 17 nov. 2001)

No exterior, a exposição chamou a atenção da mídia. Boa parte dos artigos ressaltava a cenografia de Jean Nouvel, que mergulhou as peças barrocas na escuridão, num Guggenheim pela primeira vez pintado de preto. Mas sobre a arte e a cultura brasileiras, objetos da exposição, o que se disse?

A crítica publicada por Artforum, uma das revistas de maior prestígio internacional, foi arrasadora: "nunca arte tão boa pareceu tão ruim". O artigo diz, a título de conclusão, que talvez a exposição fosse incentivar o turismo e atrair investimentos para o Brasil, mas que a "imagem perversa oferecida pela exposição seria difícil de ser superada" (Adriano Pedrosa, mar. 2002).

O New York Times observou que, apesar de tudo, era muito bom ter acesso a obras de artistas absolutamente desconhecidos (e o crítico se referia a artistas como Tarsila, Rego Monteiro, Portinari, Oiticica, Lygia Clark, enfim, todos esses artistas que os brasileiros tendem a ver como altamente 'internacionais'). Mas o jornal prossegue:

Fisicalidade, espetáculo, erotismo casado à espiritualidade e excesso: esses clichês da cultura brasileira estão todos presentes na exposição. (New York Times, 26 out. 2001)

Um outro periódico, bem menos conhecido, observa o impacto da colonização espanhola (!) sobre a produção cultural brasileira e termina dizendo:

Após ver Brazil Body and Soul, o visitante terá certamente vontade de visitar uma igreja ou pelo menos o Carnaval! (Lauren Fresco, The Daily Targum, 27 jan. 2002)

Assim sendo, qual seria o balanço desse tipo de evento? Quem ganha e quem perde? Qual o preço a ser pago? 
Talvez as declarações de Edemar Cid Ferreira, grande articulador do projeto, possam servir a essa reflexão:

O que falta à arte contemporânea brasileira é o marketing que os países ricos fazem. Eu trabalho para que, em alguns anos, o Brasil seja um dos primeiros países a ser citado quando a questão for arte contemporânea.

Mas ele afirma também:

Eu quero melhorar a imagem do Brasil no exterior. No exterior, o Brasil é conhecido pela destruição de suas florestas, pelas crianças de rua, pela violência. Eu quero mostrar um Brasil diferente, vencedor no seu extraordinário passado cultural. Um país só é respeitado se for conhecido. Nós vamos conquistar este respeito, e, até 2005, o Brasil terá uma visibilidade como nunca teve antes, e nós vamos estabelecer laços e relações comerciais com o mundo inteiro. (Entrevista a Diogo Mainardi, Veja, 20 jun. 2001)

\section{Mira Schendel/Tunga à la Galerie Jeu de Paume}

A exposição Tunga e Mira Schendel, na Galerie Jeu de Paume, seguiu um percurso próximo de Brazil Body and Soul, consideradas as devidas proporções.

Quando os agentes de Brasil Connects ${ }^{29}$ foram à França e foram apresentados aos diretores de museus e instituições francesas (pela mão da Embaixada do Brasil na França), o diretor da Galeria Jeu de Paume, Daniel Abadie, ficou entusiasmado. ${ }^{30}$

Ele queria, já fazia tempo, realizar uma exposição de um artista brasileiro, mas não tinha os meios necessários. Quando foi então convidado para uma recepção na Embaixada e depois, quando conversou com os curadores de Brasil 500 Anos, viu a possibilidade de seu projeto tomar forma.

A Fundação Brasil 500 Anos tinha, na verdade, apresentado um outro projeto, recusado por Abadie, que, por sua vez, sugeriu a realização de Tunga/Mira Schendel. ${ }^{31}$ A contrapartida de Brasil 
Connects, segundo a instituição, foram as despesas com seguro e transporte de obras e pessoal.

Abadie deixou claro que era "sua idéia" e "seu projeto", desenvolvidos em colaboração com uma empresa capaz de fornecer uma boa logística, recursos e ainda servir de antena no Brasil para projetos futuros. $^{32}$

A Associação (Brasil 500 Anos) é uma organização extremamente complexa e que dispõe de meios e de uma logística excepcionais, de um profissionalismo sem equivalente, o que permite o desenvolvimento de projetos em todo o mundo. Eles têm grande interesse em colaborar conosco e nós estamos muito contentes de ter o seu apoio.

Apesar dos projetos em "colaboração" e das trocas constantes com o Brasil, ${ }^{33}$ a Galerie tem uma participação pouco expressiva de especialistas brasileiros, cujo parecer não é levado em conta. Ainda segundo Abadie, em entrevista no dia 31 de julho de 2001, o problema é lingüístico: "os críticos e curadores brasileiros escrevem em português e nós não lemos português, infelizmente!"

Contudo, a língua portuguesa não é obstáculo na negociação do financiamento para seus projetos. ${ }^{34}$

Aqui vemos perfeitamente qual a relação de poder e o mercado de interesses de uma e de outra parte. O discurso, entretanto, é sempre no sentido da prevalência dos critérios de excelência, do valor absoluto da arte e uma recusa de toda e qualquer objetivação dos interesses manifestamente existentes para além do projeto artístico.

(...) o que nos interessa é a arte: a escolha de um artista se faz porque o artista é extraordinário e não tem nada a ver com sua origem. Os artistas brasileiros expostos foram apresentados devido ao caráter único e excepcional de suas obras. As iniciativas que levam em conta a dimensão identitária não funcionam: eu mesmo recusei recentemente uma exposição oferecida pelo país $\mathrm{X}$, não existe arte de um país ou de um continente, o que existe é boa ou má arte. 
Mas num outro momento ele constata:

Eu estou certo de que na América Central e na América do Sul há uma dinâmica artística extraordinária, é de onde vem a produção artística mais interessante, mais excitante, o que é uma constatação, se olharmos as estatísticas, constatamos isso, não posso explicar.

Os discursos podem ser contraditórios e são utilizados de acordo com a ocasião e o interlocutor. Mas por trás dos discursos, na prática, a arte do Brasil, da América Latina (e de outros países, como recentemente a da China) são, na verdade, fonte de novos recursos para a instituição - recursos estéticos, simbólicos, econômicos.

Apesar de todos os interesses subjacentes, a Galeria Jeu de Paume é ainda assim uma boa vitrine. Muitos artigos foram publicados sobre a exposição. O trabalho de Tunga, sobretudo True Rouge, chamou a atenção da crítica francesa, mais ou menos familiarizada com o artista. Mira Schendel ficou um pouco ofuscada, mas também foi objeto de artigos e críticas.

Em relação aos dois artistas, o fato de um ser casado com uma francesa e a outra ter uma origem européia foi freqüentemente destacado. Quase nenhuma crítica ousou tocar em questões relacionadas às especificidades de uma arte ou história da arte brasileiras (desconhecidas da grande parte da crítica francesa).

Isso mostra, de certa forma, que mesmo os críticos que se interessam pela produção artística do Brasil têm pouca informação a respeito das especificidades dessa produção e, em consequiência, acabam se apoiando em fatos que podem criar uma impressão de familiaridade, como é o caso dos vínculos familiares europeus. Isso mostra também que a história da arte 'universal', mesmo contemporânea, tem sistematicamente excluído a produção brasileira.

$\mathrm{O}$ artigo do historiador da arte Paul Ardenne toca em alguns pontos cruciais a respeito da inserção dos artistas brasileiros no circuito internacional: 
O império das modas e o mercado têm efeitos perversos. A eleição circunstancial de artistas 'exóticos' é um deles, esse exotismo é freqüentemente o único critério de excelência.

O boom latino, observado em Nova Iorque, aproximadamente em 1995, propulsou vários artistas, cuja emergência trouxe um pouco de ar fresco, mas pouca arte válida.

De origem brasileira, Tunga faz parte desses artistas 'exóticos'. (...) Tunga, antes de tudo, tem uma força inventiva plástica pouco comum, fator que, para o expectador, é freqüentemente desestabilizador....

Mas, apesar de uma crítica bastante lúcida e, em certos aspectos, elogiosa, Ardenne termina por comparar Tunga com Louise Bourgeois, em detrimento do artista brasileiro.

Os contornos de um simbolismo sustentado sensível pode incomodar pelo aspecto anacrônico, para dizer fácil (esse é um ponto que explora, por exemplo, Louise Bourgeois, cujo objetivo é mais inteligível do que o do artista brasileiro). (Paul Ardenne, Art Press, p. 78-79), dez. 2001.

\section{Hélio Oiticica: quasi-cinemas}

Essa exposição foi organizada pelo New Museum, em colaboração com o Wexner Center for the Arts e o Kölnischer Kunstverein, e apresentada em Nova Iorque de 27 de julho a 13 de outubro de 2002.

O New Museum é conhecido como uma das instituições mais abertas e democráticas da cena artística internacional americana. Mesmo os críticos e curadores latino-americanos engajados, herdeiros de uma crítica da resistência, à qual eu já me referi, concordam em apontar o museu como um espaço à parte, aberto, interessado pela produção de outros países. ${ }^{35}$

Para o New Museum, a única possibilidade para a arte hoje é ser global: 
The program of dynamic solo exhibitions and landmark group shows definitive key moments in the development of contemporary art, reflects the global nature of art today and spans a vast array of cultural activities and media. The Museum is guided by the conviction that contemporary art is a vital social force that extends beyond the art world and into the broader culture. (Texto de apresentação no site do museu: www.newmuseum.org)

De acordo com essa perspectiva, o museu convida constantemente artistas de todos os continentes e também, o que é ainda raro, curadores vindos de outros países não-centrais. Atualmente, o crítico cubano Gerardo Mosquera é curador adjunto. Dan Cameron, curador principal, viaja a maior parte do seu tempo e participa de projetos no mundo todo. ${ }^{36}$

Entretanto, de acordo com uma análise feita anteriormente, observei que o New Museum abre somente 30\% de sua programação à arte não-americana. E, quando eles organizam uma exposição dedicada a um artista de fora, as interpretações mais freqüentes dizem respeito à influência da América sobre a produção dos artistas (cf. Fialho, 2004). Os curadores convidados também são, em geral, ligados aos Estados Unidos ou tiveram uma formação nesse país.

E o caso da exposição Helio Oiticica: Quase-Cinemas não é diferente.

O projeto da exposição foi criado por Dan Cameron e Carlos Basualdo, ${ }^{37} \mathrm{e}$ a escolha das obras, centrada na produção nova-iorquina de Oiticica. A sua apresentação realça sobretudo a influência da cultura e do ambiente americanos sobre a produção do artista.

As relações entre a obra de Hélio com a de artistas americanos, como Jack Smith e Andy Warhol, são lembradas freqüentemente nos ensaios do catálogo e nas discussões organizadas pelo museu sobre a exposição, assim como na imprensa. As referências à história da arte brasileira são mínimas e reproduzem uma fórmula freqüentemente utilizada como síntese da arte brasileira, com duas ou três palavras sobre o neoconcretismo. 
O mais espantoso é que, apesar da evidente falta de informação sobre a arte brasileira e sua história, assim como sobre a trajetória de Oiticica, e ainda mais sobre o contexto de sua produção artística, o museu não se valeu de especialistas brasileiros na matéria, que não participaram da confecção do catálogo, da produção da exposição ou das atividades suplementares. E isso explica as distorções feitas.

Hélio foi mais transgressor que Andy Warhol na desconstrução dos mitos e jamais teve a intenção de copiar Jack Smith. (Revista Época, 10 mar. 2003)

O descontentamento expresso por César Oiticica, curador do Projeto Oiticica e sobrinho do artista não é sem razão.

O Projeto Hélio Oiticica organizou, alguns meses depois, uma exposição na Pinacoteca do Estado, em São Paulo, que foi de certa forma uma 'resposta' à redução e simplificação apresentada pelo New Museum.

Em Nova Iorque, somente Paulo Herkenhoff, na época curador adjunto do MoMA, foi convidado, na noite de $1^{\circ}$ de agosto de 2002, para uma mesa redonda com Dan Cameron, e, na ocasião, ele observou claramente seu desacordo com a "americanização" da produção de Oiticica.

Mas talvez seja justamente essa "americanização" 38 que faça com que a obra do artista seja integrada à cena internacional:

(...) his experiment with pop culture and cinema, influenced by and responding to such artists as Andy Warhol, Jack Smith....

In 1973, the full development of the Cosmococa are extremely reflective of this shift into the urban environment of New York, no longer in the street, participating in this intense urban interplay of the life of the favelas in Rio, but coming into the interior spaces of New York. It is a very fundamental transformation... (Gary Garels, chief curator of Drawings and curator of Painting and Sculpture at the Museum of Modern Art, 2002)

Um artigo publicado no New York Times faz uma análise que é a síntese de muitas outras análises feitas sobre Oiticica no exterior, resumindo o artista brasileiro a um simples arremedo de Warhol: 
...influenced by the performances by Yvonne Rainer and Yoko Ono, the works by Robert Smithson, Gordon Matta-Clark, Dan Graham and Peter Campus. He befriended Jack Smith, whose four-hour slide shows in his loft in the East Village made a particularly big impression on him. So did John Cage and Andy Warhol: Oiticica seems almost to have wanted to be a Brazilian Warhol, to create his own Factory, to make his own version of Warhol's films, to immerse himself in the whole Warholian universe of underground gay culture, drugs and celebrity. (Kimmelman, 2003)

\section{Un art populaire}

Uma possibilidade de "distinção" da parte das instituições internacionais, além da integração de artistas vindos de países "exóticos", é a proposição de exposições nas quais as categorias modernas, próprias à história da arte, são excluídas ou desafiadas.

Essa é a linha adotada pela Fondation Cartier, que expõe quadrinhos, documentários, arte popular, arte indígena, tudo sob o grande guarda-chuva da "arte contemporânea". Essa escolha conceitual tornou-se a marca desse museu.

O Brasil e seu "exotismo", nesse caso, servem perfeitamente para demonstrar a abertura, o ecletismo, a diversidade que a instituição quer oferecer.

Desde 2000, a Fondation Cartier já realizou 3 exposições acerca do Brasil: Alair Gomes (2001), Un art populaire (2001) e mais recentemente Ianomamis, l'esprit de la fôret (2004).

Hervé Chandès, diretor, é um apaixonado pelo Brasil, país que visitou muitas vezes. A preferência pelo Brasil não é de todo espontânea. Gilberto Chateaubriand, um dos grandes colecionadores de arte brasileira, faz parte do conselho da instituição e realiza doações regulares, além de convidar freqüentemente Chandès e outros curadores ao Brasil.

A idéia da exposição nasceu com uma visita de Hervé Chandès à Mostra Brasil 500 anos. Chandès ficou impressionado pelo segmento 
de arte popular, "sa richesse, sa diversité, sa modernité fut à l'origine de ce projet" (Catálogo da exposição Un art polulaire, 2001).

A equipe da Fondation Cartier foi, depois disso, muitas vezes ao Brasil para preparar a exposição, visitar ateliês de artistas e de colecionadores. Gilberto Chateaubriand foi sempre o mediador desses encontros, "foi ele quem apresentou as pessoas, com ele as portas estão sempre abertas”, segundo Hélène Kelmachter, em entrevista feita em 2001. Para as obras de Bispo do Rosário, o mediador foi Emmanuel de Araújo, diretor da Pinacoteca do Estado de São Paulo na época, com quem Hervé Chandès já havia trabalhado.

A exposição reuniu mais de 130 obras e 37 artistas da Europa, da África, da Ásia, da América do Norte e do Sul. A intenção era "oferecer um olhar sobre a arte popular hoje" (Catálogo da exposição Un art polulaire, 2001). No conjunto, os artistas brasileiros eram a maioria: 14 , sendo que um foi escolhido para aquisição - Adalton Lopes.

A maior parte dos artistas brasileiros nunca havia saído do Brasil. As exposições das quais haviam participado eram, em geral, exposições que utilizavam categorias da história da arte que os colocavam em um nível diferente dos artistas: loucos, ingênuos, brutos. Em Paris, pela primeira vez, eles se tornaram 'artistas contemporâneos'.

A Fondation Cartier pretendia revelar a modernidade desse campo da criação, ressaltando a maneira como a arte popular se infiltra na arte contemporânea:

A escolha das obras foi feita antes de tudo pela qualidade estética, as obras repertoriadas escapam a uma categoria rígida, dão as costas às etiquetas que tendem a manter a arte popular fora do campo da arte contemporânea. (Catálogo da exposição Un art polulaire, 2001)

Para isso, a exposição colocou, no mesmo espaço, artistas contemporâneos pertencentes aos mais altos círculos institucionais e do mercado e artistas populares, em grande parte, desconhecidos. 
A reflexão sobre a relação entre arte popular e arte contemporânea não faz parte da tradição francesa, disse Hélène Kelmachter, uma das curadoras da Fondation Cartier, em entrevista feita em 2001. Mas essa reflexão faz parte da tradição brasileira, o que ela ignorava.

Apesar do seu discurso, a Fondation Cartier não conseguiu escapar das categorias que ela diz ultrapassadas: os artistas contemporâneos escolhidos são ocidentais e trabalham nos principais centros internacionais. A cultura popular é apenas uma das possíveis referências para trabalhos de natureza conceitual de artistas americanos ou europeus. Do outro lado, os artistas populares vêm do Brasil, da África, do México...

Há, sem dúvida, uma diferença entre Adalton Lopes, que tem problemas cognitivos e origem modesta, e Liza Lou, artista americana com uma boa cotação no mercado internacional.

O resultado é finalmente bastante desigual: a arte popular é a arte dos países periféricos e a arte contemporânea é a arte dos países do centro, sendo que as obras apresentadas, representativas da cultura popular servem primeiramente para valorizar a produção de artistas contemporâneos já consagrados.

\section{Conclusões}

Apesar dos discursos às vezes demasiado otimistas ou, com freqüência, simplesmente hipócritas, a arte brasileira ocupa uma posição coadjuvante na cena internacional.

Há uma grande distância entre a maneira como a mídia, os atores culturais e até mesmo alguns importantes intelectuais representam o lugar da arte brasileira a nível internacional e o lugar efetivamente ocupado pelo Brasil (cf. Miceli, 2002).

Se, por um lado, o número de eventos se multiplicou nos últimos anos, isso não significa que a cultura brasileira seja mais valorizada 
no exterior. A presença da arte brasileira é sobretudo efeito de uma demanda dos mercados, dos quais o Brasil participa sobretudo como produtor de matéria-prima.

A análise das determinantes de produção e a realização de projetos em torno da cultura brasileira - o papel e os interesses dos diferentes agentes envolvidos - mostra que, por trás de cada projeto artístico, há um grande mercado de bens políticos, diplomáticos, econômicos e simbólicos (Bourdieu, 1984).

Os museus buscam uma certa distinção ${ }^{39}$ num cenário no qual espaços e eventos artísticos se multiplicam, buscam recursos para completar seus orçamentos constantemente deficitários; os curadores, os críticos, os historiadores da arte buscam novas categorias a serem exploradas e novos mercados de trabalho; as galerias e os artistas se beneficiam de um mercado internacional que aumenta a cotação das obras; as empresas fazem marketing indireto com custos mínimos e assim por diante.

Sempre perseguindo uma entrada no mundo internacional da arte, o sistema brasileiro das artes aceita o discurso pós-colonialista sem protestar, sem buscar construir seu próprio discurso.

A fim de participar da cena internacional, os agentes brasileiros estão, em geral, sempre prontos para fazer concessões excessivas: aceitar e/ou participar na promoção de estereótipos da cultura brasileira; pagar caro, muitas vezes com dinheiro público, o 'aluguel' de espaços de legitimação; aprender a sua própria história com os agentes internacionais mal informados; abrir a cena nacional para agentes internacionais oportunistas, etc.

É necessário ter consciência para, eventualmente, reverter essa tendência.

É necessário ultrapassar o sentimento de orgulho nacionalista que nos dá uma imagem da cultura brasileira que não corresponde à imagem dada pela maior parte dos eventos realizados no exterior. 
E isso passa sobretudo pela definição de uma política cultural visando à participação mais efetiva de nossos pesquisadores, professores, críticos, curadores nos projetos internacionais. É necessário se construir um banco de dados em que possam ser acessadas as informações sobre esses eventos, passados e futuros, para que se evite a repetição dos mesmo erros.

Pesquisas de campo são também fundamentais para se evitar as análises intuitivas ou de cunho nacionalista. Pesquisas como as apresentadas neste evento, além de encontros com nossos colegas, intercâmbios com outros países não centrais, colaborações Sul-Sul (tal como vem propondo o presidente Lula).

Do contrário, sempre haverá um especialista europeu ou americano a nos explicar o que é a arte brasileira, vista sempre sob a perspectiva americano-euro-centrista.

E para finalizar, uma sugestão: seria necessário talvez superar nosso passado antropofágico. A Antropofagia, nos parece, tornou-se um conceito por demais aberto e tem sido usado para justificar a importação de modelos que nos são, na verdade, impostos.

\section{Notas:}

1 Com a sucessão de períodos de esplendor na Itália, na França, na Espanha, na Inglaterra, na Holanda, no Império Austro-Húngaro, etc.

2 Existe uma extensa bibliografia sobre o assunto. A título indicativo, ver Guibault (1988); Cohen-Solal (2000).

3 Mário Pedrosa descreveu, em 1968, por ocasião da Bienal de Veneza, quando, pela primeira vez, um latino-americano obteve o grande prêmio, a reação da França e de outros países europeus, que utillizaram até mesmo argumentos racistas para desqualificar o argentino Julio Le Parc. Ver: Pedrosa (1986).

4 Esse tema está mais desenvolvido no artigo "Identity and territorial representation in contemporary art institutions: the gap between discourse and practice", apresentado pela autora em outubro de 2003 na New School, em Nova Iorque, no seminário Museum and Society, 
presidido por Vera Zolberg, cujo resumo foi publicado pelo Centre for Brazilian Studies University of Oxford.

5 O que faz com que os Estados Unidos tenham se voltado para a América Latina, e a Europa, mais para a África, por exemplo.

6 E isso ainda é válido hoje. Tanto no mundo da arte como no mercado, novas 'marcas' são incessantemente (re)inventadas, categorias perdem valor e são substituídas por outras, etc.

7 As primeiras teses são defendidas, exposições dedicadas à arte "nãoocidental" se multiplicam, surgem mais galerias especializadas, são criados os departamentos especializados na Christie's et Sotheby's, etc.

8 Mario Pedrosa, Frederico Morais, Marta Traba, Cildo Meireles e tantos outros críticos e artistas fizeram parte desse grupo.

9 A reflexão sobre a noção centro-periferia que está mais desenvolvida no artigo "Artistes brésiliens dans les hauts lieux de l'art contemporain: la preuve de la globalisation ou fait d'exception confirmant l'exclusion?" apresentado no Interim Meeting of the International Sociological Association \& European Sociological Association - New Trends of the Sociology of the Arts, Paris, 14 a 18 abril 2003.

10 J. H. Martin foi o encarrego da programação do Musée des Arts d'Afrique et d'Océanie de Paris (1994-1999) e, desde janeiro de 2000, é o diretor do Museum Kunst Palast de Düsseldorf.

11 Exposição apresentada no Musée National d'Art Moderne - Centre Georges Pompidou e no Grande Halle de la Villette, de 18 de maio a 14 de agosto de 1989. Dessa exposição, que marcou data, participaram Cildo Meireles e Mestre Didi.

12 Tema da Bienal de Lyon de 2001. Dois artistas brasileiros foram selecionados: Tunga e Miguel Rio Branco.

13 As referências nesse campo são abundantes. Ver especialmente McEvilley (1999).

14 Denominação usual para indicar a produção artistica de países periféricos, estejam eles na África, América do Sul ou Ásia... O conceito de arte nãoocidental requer uma análise bem mais aprofundada, que venho desenvolvento em outros artigos, mas sobre o qual não me estenderei aqui.

15 Como dizia Bourdieu, "la reconnaissance va toujours à ceux qui l'ont déjà". 
16 Minha análise é prioritariamente sociológica, portanto não comporta nenhum julgamento de valor em relação aos projetos artísticos, às obras ou aos artistas.

17 Estima-se em 8 milhões de dólares, pagos pela Fundação dos Amigos da Associação Brasil 500 Anos, com utilização da lei Rouanet, ou seja, dinheiro público.

18 Fundação criada pelo banqueiro Edemar Cid Ferreira sob o nome de Brasil 500 anos, teve como primeira missão comemorar o $5^{\circ}$ Centenário da 'descoberta' do Brasil. Transformada em Brasil Connects, a fundação ampliou seus objetivos e hoje desenvolve projetos nas áreas da cultura e meio-ambiente, no Brasil e no exterior, já tendo organizado eventos na França, na Inglaterra, no Chile, em Portugal, na Espanha, na Itália, na Argentina, etc.

19 Inaugurada em São Paulo, em 2000, a gigantesca mostra se desdobrou em inúmeras exposições de menor porte no Brasil e no Exterior.

20 Excluída a arte do século XIX, havia um pouco de tudo: arte moderna e contemporânea, objetos indígenas, arte «afro-brasileira», artesanato, arte popular, objetos religiosos.

21 Latin American Art of the Twentieth Century. Edward Sullivan também publicou livros sobre arte mexicana e arte da República Dominicana.

22 A representação brasileira na Bienal de Veneza, cujo curador foi Germano Celant, custou mais de um milhão de dólares e mostrou, além de arte contemporânea, Carmen Miranda e o Carnaval.

23 Nos parece pertinente aqui fazer um parêntese sobre a Bienal de São Paulo, que até sua XXIV edição - Antropofagia, cujo curador foi Paulo Herkenhoff - sempre teve curadores brasileiros e que hoje em dia convida curadores internacionais a cada edição. A XXV edição teve Alfons Hug como curador-geral. Até agora, entretanto, nós não tivemos nenhum curador brasileiro convidado para fazer a curadoria de outras Bienais e menos ainda para escolher a representação nacional de outro país.

24 Um outro evento, que provocou menos barulho, foi a construção do Museu Rodin em Salvador. Valeria a pena verificar quais foram as condições do contrato entre o museu francês e a cidade de Salvador.

25 Julian Zagazagoitia, mexicano, atualmente diretor do Museo del Barrio, em Nova Iorque, era encarregado de projetos internacionais no Guggenheim na época da exposição Body and Soul. 
26 Curadora francesa que trabalha em Rotterdam e que se interessa pela arte brasileira, já tendo desenvolvido muitos projetos no Brasil.

27 Entrevista, em dezembro de 2003, com Luis Canmitzer, uruguaio, crítico de arte, artista e curador do Drawing Center em Nova Iorque.

28 No Brasil outros curadores internacionais trabalham sobre projetos diversos. Às vezes eles não são especialistas nos seus países de origem mas se tornam especialistas no Brasil, tal como Alfons Hug, diretor do Instituto Goethe e que se tornou curador; o ex-attaché cultural da França, Romaric Buel, produtor cultural, curador da exposição Paris 1900, que apresentou com sucesso, em várias capitais, obras da coleção do Petit Palais, enquanto este estava em reformas e precisava de um lugar para o acervo.

29 Edemar Cid Ferreira, Nelson Aguilar e Franklin Pedroso.

30 Entrevista com Daniel Abadie, em 31 de julho de 2001.

31 Mais tarde, Abadie também propôs uma exposição dedicada a Niemeyer, e Cid Ferreira pediu para participar da co-produção.

32 Efetivamente, a Galerie Jeu de Paume realizou a exposição dedicada a Niemeyer e, em 2003, organizou uma grande retrospectiva de Artur Bispo do Rosário.

33 A Galerie Jeu de Paume trabalhou com o Brasil várias vezes. Segundo Daniel Abadie, organizaram exposições no Rio e em São Paulo, em Curitiba, em Salvador, em Brasília. As exposições são sempre concebidas na França e exportadas para o Brasil. O Brasil e outros países periféricos (a Galerie trabalha freqüentemente com a América Latina e Central) importam exposições da França ou enviam as obras e os artistas, mas não participam no desenvolvimento dos projetos.

34 Abadie tem uma boa circulação na esfera política. Ele obteve, do Ministério da Cultura brasileiro, apoio para a realização do artista Antonio Manuel. Ele foi, na ocasião, recebido pelo ministro Weffort, tipo de tratamento que certamente outros curadores, no Brasil, não tiveram.

35 Luis Canmitzer e Gerardo Mosquera, críticos latino-americanos militantes, têm boas relações com o New Museum.

36 Ele foi o curador da útlima Bienal de Istambul (2003). O conceito da exposição era baseado na idéia de 'Justiça Poética', o que deveria dar à arte um papel social, quase humanitário. 
37 Basualdo é um curador de origem argentina que teve uma formação nos Estados Unidos. Hoje ele é curador do Wexner Center for the Arts, em Ohio, Estados Unidos.

38 Ver também: Fialho (2002).

39 Aqui expandimos o conceito de Pierre Bourdieu em La distinction: critique sociale du jugement (1979).

Abstract: International exhibitions of Brazilian art: speechs, practices and interests involved

During the 1990's, the presence of Brazilian Art became more and more visible in the international art scene. Curators and other international agents adopted a kind of "politically-correct" discourse according to which borders between center and periphery - that always organized the international artistic field - would disappear, thus allowing peripheral art to enter the most prestigious institutions of central countries. Nevertheless, most of the exhibitions, including Brazilian art, do not correspond to a democratization of the international artistic field and do not help to promote Brazilian art internationally. In fact, they reflect the perverse consequences of globalization, serving to raise the prestige and the economic power of a few institutions and individuals and to reduce Brazilian culture to stereotypes. In order to illustrate this idea we will analyze the following exhibitions in this paper: Brazil Body and Soul (Guggenheim Museum, New York), Hélio Oiticica Quasi-Cinemas (New Museum, New York), Un art populaire (Cartier Foundation/ Paris), Tunga and Mira Schendel (Galerie National du Jeu de Paume, Paris).

Key-words: Brazil, art, culture, international exhibition.

\section{Bibliografia}

BOURDIEU, Pierre. La distinction: critique sociale du jugement. Paris: Editions de Minuit, 1979.

A economia das trocas simbólicas. São Paulo: Perspectiva, 1984.

COHEN-SOLAL, Annie. Un jour ils auront des peintres: l'avènement des peintres américains: Paris 1867 - New York 1948. Paris: Gallimard, 2000. 
FIALHO, Ana Letícia. Identity and territorial representation in contemporary art institutions: the gap between discourse and practices. In: Research abstracts 2004. Oxford, Centre for Brazilian Studies University of Oxford, 2004.

- Artistes brésiliens dans les hauts lieux de l'art contemporain: la preuve de la globalisation ou fait d'exception confirmant l'exclusion? Livro de resumos do Interim Meeting of the International Sociological Association \& European Sociological Association New Trends of the Sociology of the Arts, Paris, abril de 2003.

Hélio Oiticica volta à cena internacional amaricanizado. 2002.

Disponível em: 〈www.artewebbrasil.com.br〉.

GARELS, Gary. [speech]. In: NEW MUSEUM OF CONTEMPORARY ART. Critical Voices Series: Hélio Oiticica exhibition "Quasi-cinemas" that took place on 10 march 2002 at 6.30pm-8pm. Disponível em: <www.newmuseum.org/docs/oiticica.pdf>

GARRETA, Virginia (Org.). Pour une nouvelle géographie artistique des années 90. Bordeaux: Capc Musée d'Art Contemporain de Bordeaux, 2000.

GUIBAULT, Serge. Comment New York a volée l'idée d'art moderne. Nîmes: Jacqueline Chambon, 1988.

KIMMELMAN, Michale. A Brazilian's work in the 70's now looks new. New York Times, Friday, August 2, 2003.

McEVILLEY, T. L'identité culturelle en crise: art et différences à l'époque postmoderne et postcoloniale. Nîmes: Jacquelin Chambon, 1999.

MICELI, Sergio. Mercado de arte. In: MARQUES, R.; VILELA, L. H. (Org.). Valores: arte, mercado, política. Belo Horizonte: Editora da UFMG, 2002.

MOSQUERA, Gerardo (org.). Beyond the fantastic: contemporary art criticism from Latin America. London: The Institute of International Visual Art, 1996.

MOULIN, Raymonde. Le marché de l'art: mondialisation et nouvelles technologies. Paris: Flammarion, 2000.

PEDROSA, Mario. Mundo, homem, arte em crise. São Paulo: Perspectiva, 1986.

QUEMIN, A. L'art contemporain international: entre les institutions et le marché. Nîmes: Jacqueline Chambon, 2002. 
QUEMIN, Alain. L'art contemporain international: entre les institutions et le marché. Nîmes: Jacqueline Chambon; Paris: Artprice, 2002.

RAMIREZ, Mari Carmen. Beyond 'the fantastic': framing identity in US exhibitions of Latin American Art. In: MOSQUERA, G. Beyond the fantastic: contemporary art criticism from Latin America. Cambridge: MIT, 1996.

SULLIVAN, Edward. Latin American art of the Twentieth Century. London: Phaidon Press, 1996.

\section{Catálogos}

ART Populaire (Un). Paris: Fondation Cartier pour l'Art Contemporain, 2001.

BREMMER, A.; BASUALDO, C. (Org.). Hélio Oiticica: quasi-cinemas. Hatje Cantz Publishers, 2002.

MAGICIENS de la Terre (Les). Paris: Centre Georges Pompidou, 1989.

MIRA Schendel. Paris: Réunion des Musées Nationaux, Galerie Jeu de Paume, 2001.

SULLIVAN, Edward (Org.). Brasil Body and Soul. New York: Guggenheim Museum, 2002.

TUNGA. Paris: Réunion des Musées Nationaux, Galerie Jeu de Paume, 2001. 